\title{
Monitoring Floating Solar Tracker based on Axis Coordinates using LoRa Network
}

\author{
Abyan Arief Fernandez*, Andrian Rakhmatsyah, Aulia Arif Wardana
}

School of Computing, Telkom University, Jl. Telekomunikasi Terusan Buah Batu, Bandung, Indonesia

\begin{abstract}
This research aimed to build a solar tracker for a floating solar panel and used long-range (LoRa) communication to harvest energy and monitor its process. With the rising demand for renewable energy in these recent years especially for solar energy, it needs to meet this demand to remain relevant for the upcoming years where it will have an even larger impact as we shift into clean energy. Monitoring single-axis solar trackers on rural areas difficult and cost-intensive. The purpose of a floating solar farm is to reduce the cost from buying/renting land. Floating solar panels cannot be monitored using wired because they are moving nodes in the water, it makes wired installation complicated. Hence, using wireless sensor network is a solution that allows remote monitoring of floating solar panels in rural areas and makes moving nodes mentioned above possible. Testing was performed by sending 100 packets from the node to its gateway using LoRa modulation, and the gateway successfully received about $90 \%$ of the packets sent by the node. The vertical singleaxis solar tracker used in floating solar managed to get 17\% more energy than the fixed solar with a more stable income for the whole duration of sending 100 packets. C2020. CBIORE-IJRED. All rights reserved
\end{abstract}

Keywords: Vertical Single-Axis Solar Tracker, Floating Solar Farm, Wireless Sensor Network, LoRa

Article History: Received: $8^{\text {th }}$ December 2019; Revised: 30 th January 2020; Accepted: $3^{\text {rd }}$ February 2020; Available online: $1^{\text {st }}$ May 2020

How to Cite This Article: Fernandez, A.A., Rakhmatsyah, A., and Wardana, A.A. (2020) Monitoring Floating Solar Tracker based on Axis Coordinates using LoRa Network. International Journal of Renewable Energy Development, 9(2), 141-149.

https://doi.org/10.14710/ijred.9.2.141-149

\section{Introduction}

Floating solar, commonly known as Floating Photovoltaic (FPV), refers to the arrangement of solar panels whose structure floats on the water surface, usually located on a lake or river (Hui, Ho, Chan, Chan, Lo, \& Cheng, 2017). One of the reasons for building the FPV is that solar panels generally work better when cooled. If two systems are identical, one on land and one on the water surface, the performance of the one on water's surface will be better due to the much lower ambient temperature (Choi, 2014).

Because of the nature of the water surface, the small nodes of floating solar panels might be carried away or change in directions based on the currents. On the other hand, the solar panels need to always be facing the strongest light source (Heredia, Quéméré, Cervantes, Laurent, Chiappori, \& Chong, 2012). Since this problem cannot be solved by solar tracking in general, the prototype then uses a vertical single-axis tracker that can move the panel $360^{\circ}$ in an attempt to minimize the angle of incidence between the incoming sunlight and a photovoltaic panel (Luque \& Viacheslav, 2007).

With floating solar, a new problem arises in the solar monitoring system in relation to the difficulty in installation when using a wired network. In turn, this research used the wireless sensor network (WSN) as a solution. Long-range wide-area network (LoRaWAN) is a spread spectrum modulation technique derived from chirp spread spectrum (CSS) technology and is the first low-cost implementation of CSS for commercial usage (Vangelista, 2017).

While using a wired or cable connection can be a solution for the large floating solar farms, it is not viable when used on the freely floating small nodes (Sahu, Yadav, \& Sudhakar, 2016). Not only it will interrupt and restrict the movement of the node, but also it may cause unexpected accidents, such as falling upside down because of being pulled by the cable. For this, a wireless connection will be better (Lee, Schubert, Ooi, \& Ho, 2018).

LoRaWAN is defined as the communication protocol and system architecture for the network, whereas the LoRa physical layer enables the long-range communication link. LoRaWAN also manages the communication frequencies, data rate, and power for all nodes (Lora Alliance, 2018).

This research aimed to develop a monitoring system for the floating solar tracker with a LoRa-based prototype of network control system to make it possible to determine the performance of LoRa in remote communications, such as rural areas with minimum connections and to allow LoRa nodes to move freely. This research was also conducted to determine whether single-axis solar tracker

\footnotetext{
* Corresponding author: auliawardan@telkomuniversity.ac.id
} 
on the water surface can produce greater voltage than ordinary floating solar panels and whether it is feasible to use for future development.

Lee et al. (2018) studied about the monitoring of energy harvesting from floating solar panel using LoRa in a rural area. The system monitored the power generated from the solar panel and power consumption from the monitoring system.

Shuda et al. (2018) designed solar Photovoltaic (PV) monitoring system in the ground using LoRa. It aimed to monitor the efficiency of power production that was produced by solar PV. The performance measured in this study included the voltage, current, backside temperature, ambient temperature, and irradiance.

Mabon et al. (2019) designed and tested a sensor node using LoRa for solar energy monitoring system. The testing from the research measured the battery consumption from solar energy monitoring system using LoRa.

Based on the previous study, our research is more focused on the measurement of the performance of singleaxis solar tracking system in a floating solar panel and the performance of LoRa network in monitoring the floating node. The performance of both systems is important for energy harvesting. The single-axis solar tracking system is essential to identify how much voltage can be generated from the amount of light received. The LoRa communication is important to monitor the health of single-axis solar tracking system.

This research also compared the effect of power generated from floating solar panel that used single-axis solar tracking system and the one not using that system.

\section{Materials and Methods}

\subsection{Methodology}

Research began when a problem emerged while reviewing journals and conference papers about how monitoring floating solar panels on water, likes seas, rivers, and lakes. Problem exist when wired connection is used while monitoring these panels, such as high cost upon installation and maintenance of the cables for a long time. Also, the cable itself might pull on the floating solar device. Some systems have anticipated this problem by using WSN. Suwastika et al. (2016) stated that wireless sensor nodes are a suitable replacement fo wired connection when monitoring energy and other Internet of Things (IoT) based nodes, but Georgiou et al. (2017) suggested that WSN is not suitable for remote areas that cannot be reached by signals and connection from Wi-Fi and $4 \mathrm{G}$, such as in the middle of the lakes or sea surface. WSN needs battery for power. To overcome this hurdle, LoRaWAN is implemented as the modulation technique to be used in the system.

The node monitored using LoRaWAN modulation is a floating solar tracker that will also provide energy to the LoRa module as it gathers energy as a self-sustaining node. The LoRa modulation will send data gathered from the light source and voltage obtained by the solar panel (Lee \& Rahim, 2013). The function of solar trackers is to direct the solar panel or module towards the sun. These devices change their orientation throughout the day to follow the path of the sun in order to maximize the energy captured by the solar panel themselves (Bushong, 2016).
Figure 1 presents the big picture of how vertical singleaxis solar tracker works.

The function of a solar tracker is to maximize the energy gathered by the solar panel. According to a study by Rani, Singh, \& Pandey. (2018), single-axis solar tracking system is better suited because the system is less consumes battery energy than a dual-axis solar tracking system.

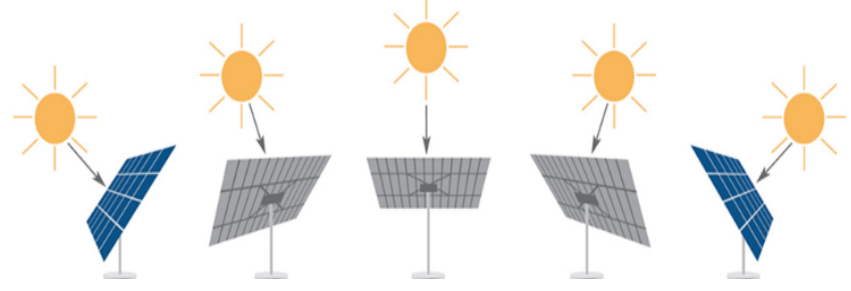

Fig. 1 Vertical single-axis solar tracker (Chin, Babu, \& McBride, 2011)

Tsao et al. (2019) stated that the sunlight has two parts: direct sunlight or sunlight, which radiates directly from the sun, making up $90 \%$ of the solar energy, and diffused sunlight, which refers to the scattered light or indirect light from the sun that can be reflected and become a large proportion in the cloudy sky.

Wang et al. (2002) revealed that the ratio in the cloudy sky between the direct sunlight and diffused sunlight is no longer 90 to 10 but 60 to 40 . It indicates that solar panels do not have to always face towards the direction of the sun, but rather find a more effective source of light, whether direct or diffused sunlight.

Shufat et al. (2016) stated that the solar tracker is useful for tracking where the light source is most effective. The task of the solar tracker mechanism is to follow the movement of the sun across the sky.

LoRa is based on the spread spectrum modulation technique derived from the CSS technology. The alliance claims to maintain low power characteristics and significantly increases communication range. The spread spectrum chirp has been used in military and aerospace communications for decades, but LoRa is the first low-cost technology implemented for commercial use (Adelantado, Vilajosana, Tuset-Peiro, Martinez, Melia-Segui, \& Watteyne, 2017).

Communication between end-devices and gateways is spread across a variety of data frequency and the channel speed. The choice of data rate is the trade-off between the range of communication and the duration of the message. Because of the spread-spectrum technology, communication with different data rates does not interfere with each other, and it creates a set of "virtual" channels that increase the capacity of the gateway. The data rates of LoRaWAN range from 0.3 to $50 \mathrm{kbps}$ (Shuda, Rix, \& Booysen, 2018).

LoRa radio chipsets use a maximum of $100 \mathrm{~mW}$ when transmitting modules 10 to $30 \mathrm{~km}$ away in the suburbs. LoRa utilizes a different spreading factor (SF) that regulates the modulation rate, thus affecting the data rate. The SF ranges from SF7 to SF12. SF7 is the fastest (5.5 kbps at $868 \mathrm{MHz}$ ) but does not have a long range, whereas SF12 is the slowest (300 bps at $868 \mathrm{MHz}$ ) but has the longest range (Augustin, Yi, Clausen, \& Townsley, 2016). 
Table 1 presents an observational data from devices commonly used for communication in Indonesia in which it is compared by the LoRa specifications. Table 2 depicts a comparison between Zigbee and LoRa:

Table 1

Comparison between Wi-Fi, 4G, and LoRa

\begin{tabular}{|c|c|c|c|}
\hline Parameter & $\begin{array}{c}802.11 \mathrm{~N} \\
\text { (Wi-Fi) }\end{array}$ & $4 \mathrm{G}$ & LoRa \\
\hline Throughput & $<300 \mathrm{Mb} / \mathrm{s}$ & $\begin{array}{l}20 \mathrm{Mb} / \mathrm{s} \\
\text { (Roughly) }\end{array}$ & $<1 \mathrm{Mb} / \mathrm{s}$ \\
\hline Range & $100-200 \mathrm{~m}$ & $2-10 \mathrm{Km}$ & $10-20 \mathrm{Km}$ \\
\hline Battery Life & Days & Days & $\begin{array}{l}\text { Weeks to } \\
\text { Moth }\end{array}$ \\
\hline
\end{tabular}

\section{Source:}

https://predictabledesigns.com/wireless technologies bluetooth wifi zigb ee_gsm_lte_lora_nb-iot_lte-m/

Table 2

LoRa vs ZigBee

\begin{tabular}{|c|c|c|}
\hline Specifications & LoRa & Zigbee \\
\hline Frequency Bands & $\begin{array}{l}863 \text { to } 870 \mathrm{MHz} \\
902 \text { to } 928 \mathrm{MHz}, \\
779 \text { to } 787 \mathrm{MHz}\end{array}$ & $\begin{array}{l}868 \mathrm{MHz}, 915 \mathrm{MHz}, \\
2450 \mathrm{MHz}\end{array}$ \\
\hline Coverage Distance & $\begin{array}{l}2-5 \mathrm{Km} \text { (urban } \\
\text { areas), } 15 \mathrm{Km} \\
\text { (suburban areas) }\end{array}$ & 10 to 100 meters \\
\hline $\begin{array}{l}\text { Power } \\
\text { Consumption }\end{array}$ & $\begin{array}{l}\text { lower compared } \\
\text { to ZigBee }\end{array}$ & low \\
\hline Modulation & LoRa & BPSK, OQPSK \\
\hline Technique & $\begin{array}{l}\text { modulation (CSS } \\
\text { modulation), } \\
\text { FSK or GFSK }\end{array}$ & $\begin{array}{l}\text { modulation. Also } \\
\text { using DSSS } \\
\text { technique to } \\
\text { convert bits to } \\
\text { chips. }\end{array}$ \\
\hline Data Rate & $\begin{array}{l}0.3 \text { to } 22 \mathrm{Kbps} \\
\text { (LoRa } \\
\text { modulation) and } \\
100 \mathrm{Kbps} \text { (using } \\
\text { GFSK) }\end{array}$ & $\begin{array}{l}20 \mathrm{kbps}(868 \mathrm{MHz} \\
\text { band), } 40 \mathrm{Kbps}(915 \\
\mathrm{MHz} \text { band), } 250 \\
\text { kbps }(2450 \mathrm{MHz} \\
\text { band) }\end{array}$ \\
\hline
\end{tabular}

Source: http://www.rfwireless-world.com/Terminology/LoRa-vsZigbee.html

Table 2 presents some significant upgrades from the more well-known communication device for rural areas. LoRa has wider bands of frequency to choose from, and its overall performance is also better. However, it has lower energy consumption, which is a straight upgrade from
ZigBee. The downside of using LoRa instead of ZigBee is that LoRa can only send a fraction of what Zigbee can do, fortunately, monitoring does not need a lot of data rate.

The reason for using a wireless connection for monitoring the data is that it will interfere with the moving and rotating nodes. With LoRa, the node will be fully independent of the cables and restrictions from land because the node itself is self-powered, thus no longer requiring any energy sent from land.

\subsection{Design Science Research Methodology (DSRM) Method}

There are some method in building the system for research, the most popular of which is the waterfall model (Wardana, Rakhmatsyah, Minarno, \& Anbiya, 2019). This model is suitable for software development, but this system will build software and hardware. Therefore, this prototype system for the floating solar tracker was built using the DSRM method. This method has been used in many information system studies (Hevner, March, Park, $\&$ Ram, 2004). This method can be very good when implemented on an information systems prototype that involves an embedded system (Omar, Trigunarsyah, \& Wong, 2009).

The first phase of the DSRM method is the identification of the problem, which is discussed in the Introduction section through the beginning phrases of the research method. The second phase is the design and development discussed in the System Overview section. The demonstration and evaluation phase will be discussed in Result and Discussion through the Evaluation section. Communication at the last phase will be discussed in the Conclusion section (Peffers, Tuunanen, Rothenberger, \& Chatterjee, 2007).

The methods of testing used to test the prototype are functional testing and quality of service (QoS) testing. First, functional testing was conducted to test if all the components used in the prototype worked as intended, whereas QoS testing will be conducted to determine if the prototype will be the right solution by testing the efficiency of the solar tracker and LoRa communication (Lavric \& Popa, 2017).

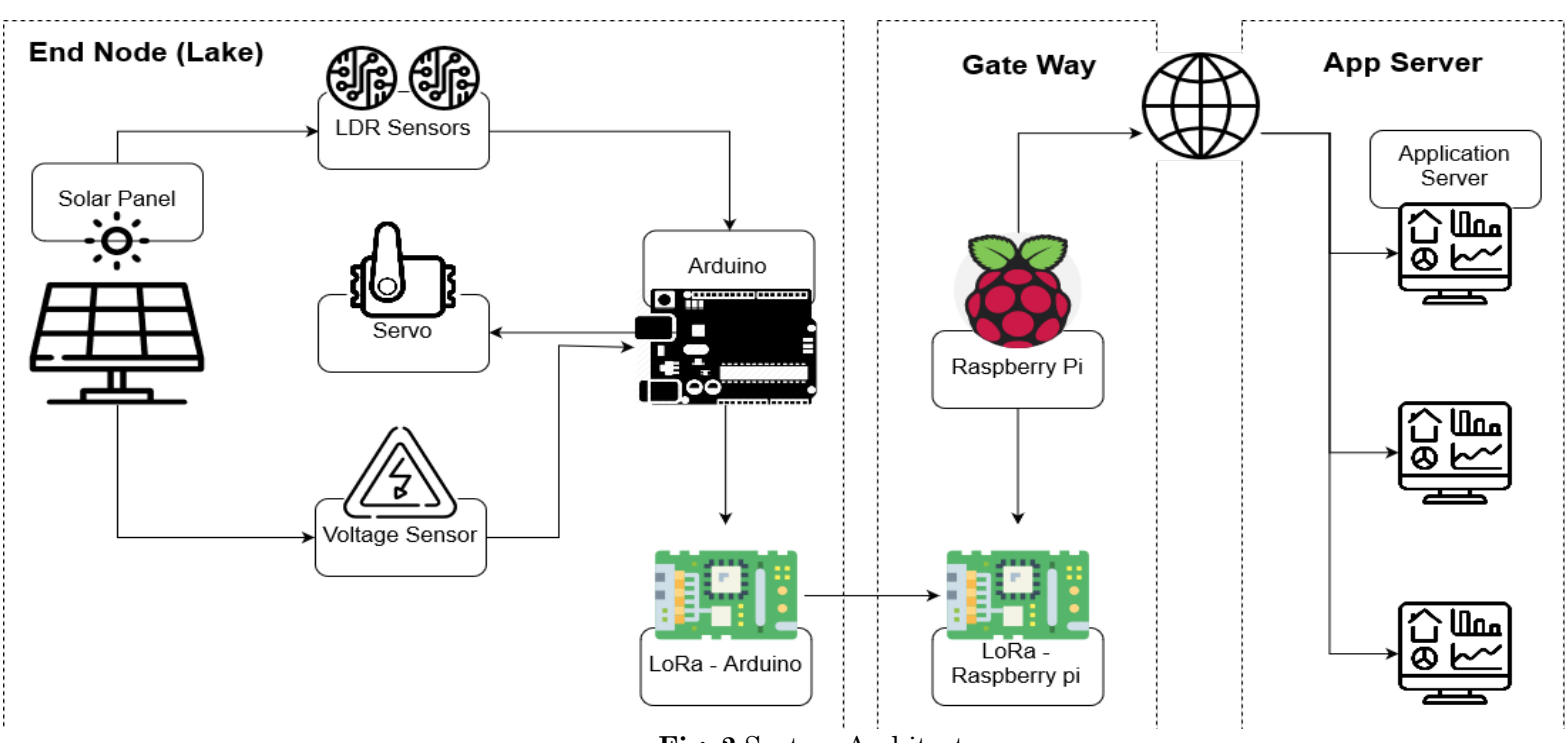

Fig. 2 System Architecture 


\section{System Overview}

Figure 2 presents the purpose of the prototype to build a solar tracker node that can be monitored using a WSN. The system architecture diagram presented in Figure 2 shows that the end node is placed on the lake without hooks and moves freely on the water surface. The LDR sensor is used to measure the light intensity that illuminates the solar panel so the solar tracker can follow the movement of the sunlight.

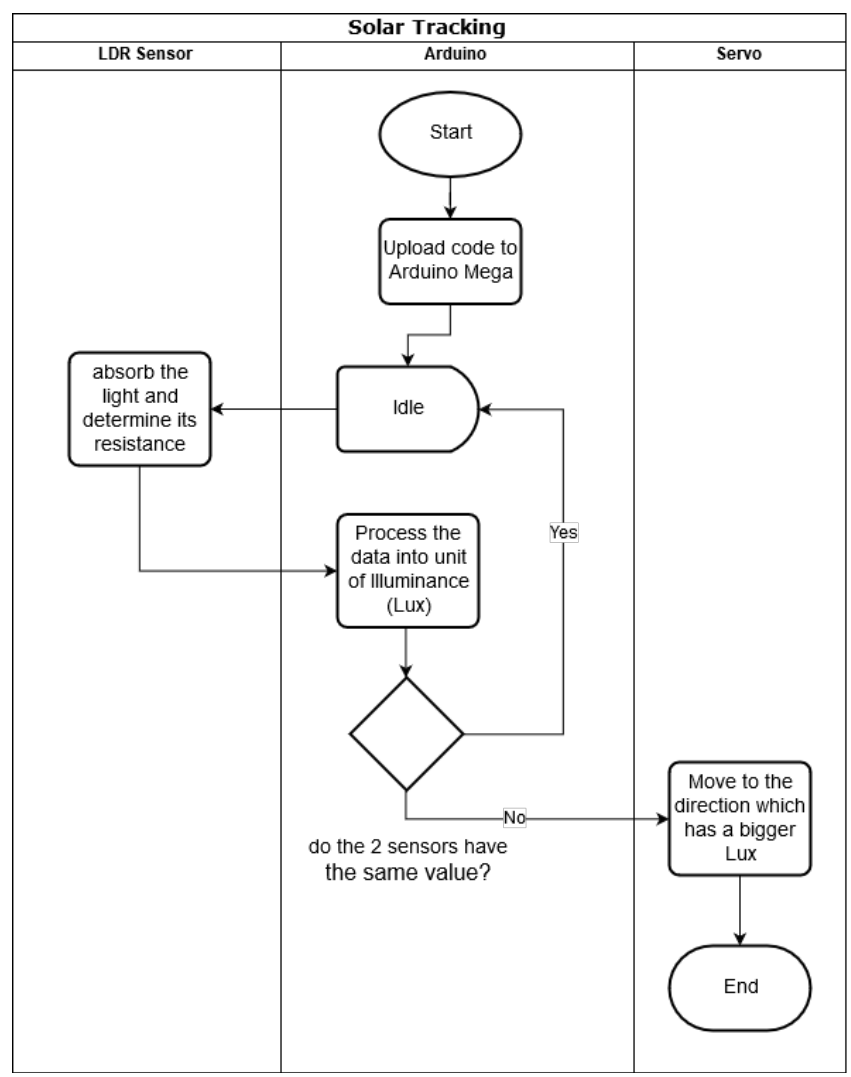

Fig. 3 Flowchart on the solar tracker system

The energy obtained by the solar panel will then be measured using a voltage sensor. The data obtained is then sent to the gateway using LoRa, which is connected to Arduino. LoRa sends data using $915 \mathrm{MHz}$ radio signals, and the data is received by thw LoRa that is connected to the Raspberry Pi Mini PC that acts both as a receiver for the data obtained and as a broker using MQTT to publish the data to network servers for the subscriber which will be displayed as a website or application server dependent on the peoplw using it. The communication protocol can be used for floating solar farms or any rural power plants to monitor the activity and power inputs via wireless connection without having to manually monitor them from time to time.

Figure 3 presents the mechanism of the vertical singeaxis solar tracker. The LDR sensors are configured into an illuminance measuring device that can detect any incoming light by lowering or rising the resistance. Then, both sensors will compare their values with each other. There are two LDR sensor found on the right and left. if one sensor has a value greater than the value of the other sensor, the solar panel will move towards a larger sensor value.
Tables 3 and 4 present the hardware and software used in the prototype respectively. LoRa module was attached to the Arduino board, which then configured itself according to the code embedded in the Arduino board and transmitted the data from the node to the receiver. The receiver itself is another LoRa module attached to a minicomputer, in this case, a Raspberry $\mathrm{Pi} 3$ as the receiver and broker for the current prototype. The Raspberry Pi was able to see the data sent and post those data on a cloud like app, in this case, mosquito used as the mediator.

Table 3

Hardware used in Prototype

\begin{tabular}{|c|c|c|}
\hline No & Name & Description \\
\hline 1 & SG90 Servo & Actuator for solar Tracker \\
\hline 2 & LDR Sensor & $\begin{array}{l}\text { Light Dependant Resistor to } \\
\text { measure the sunlight }\end{array}$ \\
\hline 3 & Solar Panel & $\begin{array}{l}\text { Module Solar Cell Mini 6v 1w } \\
200 \mathrm{~mA}\end{array}$ \\
\hline 4 & Diode & Bypass Diode $0.4 \mathrm{~V}$ \\
\hline 5 & Li-Ion Battery & 2x Lithium-ion $3.7 \mathrm{~V}$ battery \\
\hline 6 & Voltage Booster & To Boost power for LoRa - Arduino \\
\hline 7 & $\begin{array}{l}\text { Battery } \\
\text { Charger }\end{array}$ & $\begin{array}{l}\text { Charging the battery with the } \\
\text { solar panel }\end{array}$ \\
\hline 8 & Dragino LoRa & $\begin{array}{l}\text { 2x Lora Shield-Long distance } \\
\text { wireless } 915 \mathrm{Mhz} \text { with } 3 \mathrm{dBm} \\
\text { antena }\end{array}$ \\
\hline 9 & Raspberry Pi 3 & For the LoRa receiver and Broker \\
\hline 10 & Arduino Mega & $\begin{array}{l}\text { Arduino Mega } 2560 \mathrm{R} \text {, for the } \\
\text { LoRa node }\end{array}$ \\
\hline 11 & SG90 Servo & Actuator for solar Tracker \\
\hline
\end{tabular}

Table 4

Software used in Prototype

\begin{tabular}{|c|c|c|}
\hline No & Name & Description \\
\hline 1 & Arduino IDE & $\begin{array}{l}\text { Code Platform for Arduino } \\
\text { Mega and LoRa }\end{array}$ \\
\hline 2 & $\begin{array}{l}\text { Raspbian Stretch with } \\
\text { Desktop, kernel } \\
\text { Version } 4.9\end{array}$ & OS for Raspberry Pi 3 \\
\hline 3 & Python & Code used in MQTT \\
\hline 4 & Mosquito MQTT 1.4.15 & MQTT Broker Server \\
\hline 5 & $\mathrm{C}++$ & $\begin{array}{l}\text { Code used in Broker and } \\
\text { Arduino }\end{array}$ \\
\hline
\end{tabular}

The LDR sensor and servo were used as the tracking mechanism in the prototype. Two LDR sensors were attached side by side and divided by a non-see through plank and connected to Arduino. These sensors acted as eyes that located where the strongest sunlight would be. The servo acted as an actuator which would move the solar panel based on LDR sensor data. Solar panels will move toward the best sunlight.

A voltage sensor was added and used as a monitoring method to see the amount of electricity produced by the solar panel. It was attached to one side of the solar panel's 
cable and plugged into Arduino. There, the data were developed and monitored. Figure 4 presents the prototype from the floating solar tracking system.

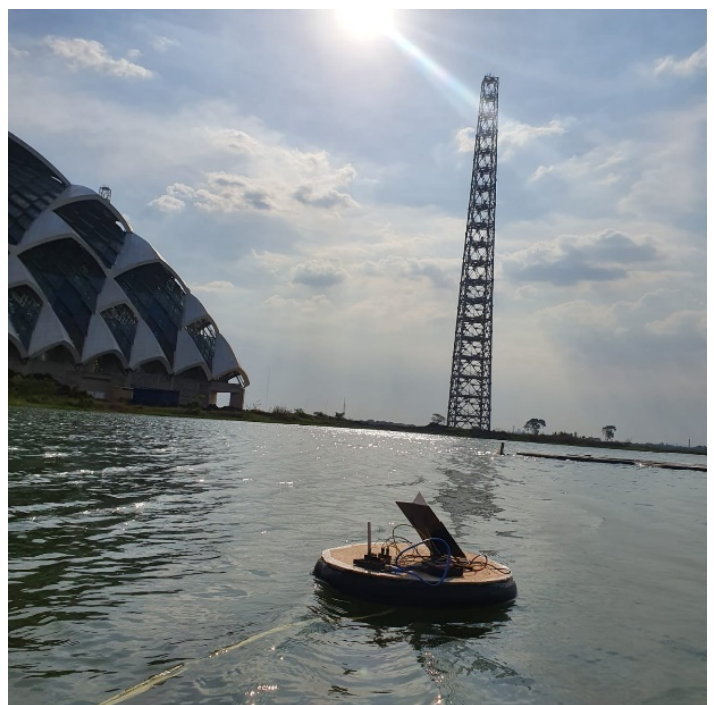

Fig. 4 Prototype floating solar tracker

Table 5

Testing Area Characteristic

\begin{tabular}{ll}
\hline Characteristic & Situation \\
Conternet & $\begin{array}{l}\text { No Wi-Fi connection whatsoever near the } \\
\text { testing site, 4G connections for specific } \\
\text { operator was still available while the other } \\
\text { operators had no connection. Radio was } \\
\text { available. }\end{array}$ \\
$\begin{array}{l}\text { Nature of the } \\
\text { region }\end{array}$ & $\begin{array}{l}\text { No tall buildings or other working space, } \\
\text { most of the areas nearby are rice fields, } \\
\text { one tall mosque and wild trees. }\end{array}$ \\
Population & $\begin{array}{l}\text { The people living near the area are either } \\
\text { construction workers or farmers and have } \\
\text { an estimate of 20-percent of the population } \\
\text { of the nearby cities such as Bandung. }\end{array}$ \\
\hline
\end{tabular}

Tests were conducted by creating a prototype using solar panels equipped with LDR sensors and voltage sensor as a source of data to be monitored. The components presented in Table 3 and the software presented in Table 4 were used in the prototype. This research used two scenarios in testing the system. The first scenario was testing the connection between LoRa when the node was not restricted and the receiver was in a fixed position. The second scenario was testing the LoRa connection when the node was moving further away from the receiver and testing the solar tracker when the node was rotating. The first testing scenario sent the data from LoRa-Arduino to LoRa-Raspberry Pi. The step-by-step scenario is presented as follows:

a. The LDR sensor detects sunlight

b. The light intensity received will be measured at what voltage the panel produces.

c. The data obtained (light illuminance and voltage) will be transmitted to LoRa-Raspberry Pi.

d. Checking whether the data emitted is complete or there are missing packets and/or errors found.

A hundred packets were sent from LoRa-Arduino node to LoRa-Raspberry pi, which would be the broker for this prototype. The packet consisted of 43 lines of string and integers. Subsequently, the packets were sent to the valid receiver. The number of packages sent by LoRa will be used as a parameter of the packet delivery ratio. After analyzing the packets, the payload was then analyzed. If any errors or incomplete strings and integers were found, then those packets would be labeled as an error and counted as error rate data. The second testing scenario was related to the accuracy and effectiveness of the singleaxis solar tracker. The step-by-step scenario is described below:

a. The sensor receives input that will be forwarded to Arduino

b. Arduino will rotate the servo until the value of the two LDR sensors are almost the same (in the same threshold).

c. The levels of effectiveness are compared when using and not using the axis.

The test was conducted twice in the clear and sunny weather between 1 and 2 o'clock in the afternoon. The test was conducted on the floating $\mathrm{Al}$ Jabbar Mosque located in Gede Bage, Bandung, Indonesia. This area was considered suitable for rural testing in research as it is located outside towns and cities and it was not an urban area, and most of its lands have been utilized for agricultural purposes. Internet connections, such as Wi$\mathrm{Fi}$, could not be found, whereas $4 \mathrm{G}$ was at a bare minimum. However, using 4G connection was still possible, but the cost would be even bigger for a constant day-to-day use.

The area has a minimum obstacle consisting of trees, rice fields, and small houses. The first test was conducted with the floating solar node placed on the water surface surrounding $\mathrm{Al}$ Jabbar Mosque and the receiver near the shore of the lake. The node in the first experiment used a vertical single-axis solar tracker with a 150 -m distance between the node and the receiver. In the second test the node was moved further away to about 300-m from the receiver without using a vertical single-axis solar tracker.

\section{Results and Discussion}

The tests used f or the system as previously mentioned are the functionality testing and QoS testing. The functionality testing measured the configuration process of the node and the LoRa modulation process, whereas the QoS testing determined whether the communication and tracking worked as intended. The discussion and evaluation will look back on how the prototype was designed and if the solution developed has been in accordance with the problem stated, as seen in the DSRM methodology.

\subsection{Prototype Functionality Testing}

Functionality testing was more focused on how the device received inputs on its electricity, commands, or data and how it responded to those inputs accordingly. Table 6 presents the functionality testing results to conclude the function of the system with the initial purpose of its development. The functionality testing that conduct for the devices and software used to determine and prove if all worked properly as intended.

As shown in Table 6 the results of the test shows that the functionality from single-axis solar tracker can work well in floating solar tracker. The third functionality test 
is sending the data from the node to the gateway. The result is LoRa managed to send data through but with packet loss and interference.

Table 6

Functionality Testing

\begin{tabular}{|c|c|c|}
\hline No & Functionality & Test Results \\
\hline 1 & $\begin{array}{l}\text { Vertical single-axis } \\
\text { solar tracker tracks } \\
\text { sunlight and rotates } \\
\text { towards it }\end{array}$ & $\begin{array}{l}\text { The servo in charge of } \\
\text { moving to the solar panel } \\
\text { to face the sun at a slow } \\
\text { rate. }\end{array}$ \\
\hline 2 & $\begin{array}{l}\text { Sensor node gets data } \\
\text { from LDR Sensor and } \\
\text { Voltage sensor }\end{array}$ & $\begin{array}{l}\text { The LDR sensor } \\
\text { successfully measured } \\
\text { sunlight and decided which } \\
\text { side was brighter. The data } \\
\text { was successfully gathered } \\
\text { by the Arduino. }\end{array}$ \\
\hline 3 & $\begin{array}{l}\text { Node sends data to } \\
\text { gateway }\end{array}$ & $\begin{array}{l}\text { The LoRa-Arduino } \\
\text { managed to send the data } \\
\text { to LoRa-Raspberry Pi. }\end{array}$ \\
\hline 4 & $\begin{array}{l}\text { The broker } \\
\text { display/saved the data } \\
\text { received }\end{array}$ & $\begin{array}{l}\text { Broker (Raspberry Pi) } \\
\text { could save the data } \\
\text { received. }\end{array}$ \\
\hline 5 & $\begin{array}{l}\text { Broker receives data } \\
\text { from the sensor node } \\
\text { (publisher) and } \\
\text { forwards the data to } \\
\text { the Subscriber }\end{array}$ & $\begin{array}{l}\text { The data from the broker } \\
\text { was uploaded to devices } \\
\text { subscribed and was in the } \\
\text { same network as the } \\
\text { broker. }\end{array}$ \\
\hline
\end{tabular}

\subsection{Test Results from the Solar Panel and Tracker}

The tests on the solar tracker were focused on the effectiveness of the voltage obtained in the time span of 100 packets with a 5 -s delay between packets sent by the node to the gateway during the daytime, with a clear sunny weather. From the data obtained between the floating solar node using vertical single-axis tracker and floating solar without a tracker, the research compared the voltage and the light illuminance.

After obtaining the voltage value from the sensor, the average value from the voltage was measured. The formula for getting average voltage value is written in the Equations 1 below.

$$
V A v g=\frac{\sum \mathrm{VTot}}{\sum \mathrm{Pct}}
$$

where:

- VAvg is the average of all voltage data,

- $\quad \sum V T o t$ is the total voltage data,

- $\quad \sum$ Pct is the total data (total packet sent from LoRa).

The second measurement obtained 100 light illuminance data from the sensor. Subsequently, the average light illuminance would be measured using the formula in Equation 2.

$$
L A v g=\frac{\sum \mathrm{LTot}}{\sum \mathrm{Pct}}
$$

where:

- LAvg is the average of all light illuminance data,

- ELTot is the total light illuminance data,

- $\quad \sum$ Pct is the total data (total packet sent from LoRa)
Figure 5 presents the graph results constructed from the data obtained from the node in Figure 4 that was successfully sent to the gateway. The following data shows the results of the solar panels using a tracking system and a fixed solar panel. When using a tracking system, the voltage generated was stable at an average of $18.316 \mathrm{~V}$, as presented by the data with straight lines. The average of the voltage that used fixed solar tracking was $18.066 \mathrm{~V}$, indicating the increase in voltage value at $1.37 \%$.

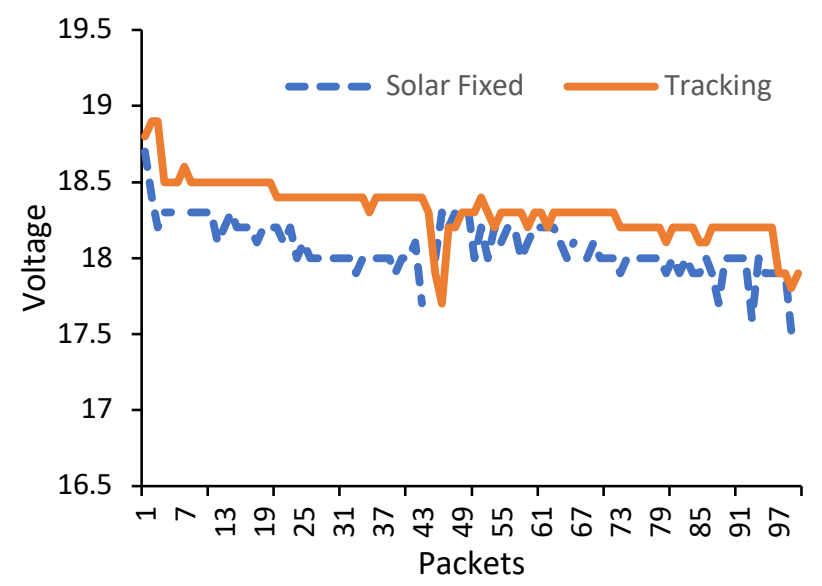

Fig. 5 Voltage produced from solar panel

The factors for the instability of the data obtained included the rotation of the buoy, probably related to water movement, winds leading the floating solar panel to on the edge of the lake, and there are trees that covered floating solar panel from direct sunlight. To see the difference experienced by the two solar panels, a light sensor was also provided to see the light intensity obtained during the experiment. The purpose of using an LDR sensor was to direct the actuator towards the direction with more sunlight.



Fig. 6 The amount of light obtained by solar panel

Figure 6 presents the data obtained from the system with and without tracking. When using solar panels, the panels exposed to high light illuminance greatly affected the voltage and energy income generated by the solar panels. In other words, the higher the illuminance of light, the higher the energy produced by the panel. On the other 
hand, the room temperature had no effect on the solar panel and was not included in the calculation. Figure 6 shows that the light illuminance obtained by the solar panel that used tracking was more stable than that obtained by the fixed solar panel.

The test data in Figure 6 determines the effectiveness of the vertical single axis solar tracker. The solar panel that used solar tracker system produced average light illuminance value of 4161.09 lux, whereas the one using a solar tracker system produced average light illuminance value of 3485.78 lux. From these data, it can be stated that the solar panel using a tracker added as much as $17.66 \%$ of sunlight and a stable income between 4000 to 5000 lux. Lux became the SI derived unit of illuminance and luminous emittance.

The results of this study are different from the research conducted by Rani et al. (2018), the solar tracker system can do efficiency by $30 \%$ when used on stable ground. In the vertical single-axis solar tracker testing and from the data obtained from the tests, it can be stated that the use of solar tracking on a floating solar node may yield more energy but not as effective in gathering energy as a normal solar tracker on stable ground would.

\subsection{LoRa QoS Testing}

Tests on LoRa connections used the following specifications: 3-db antennas with a default frequency of $9150 \mathrm{E} 5$ or $10 \mathrm{MHz}$, bandwidth of $125 \mathrm{KHz}, \mathrm{SF}$ of 12 and packet size of 51. Testing was conducted using 2 different distances of 150 and $300 \mathrm{~m}$. This test only tested LoRa connections using the default settings not the optimal distance or bandwidth settings that can be set according to Hoeller et al. (2018). The following data were obtained.

Turmudzi et al. (2019) used packet error rate (PER) and packet delivery ratio (PDR) to test and measure the performance of LoRa network. This research also used PER and PDR to measure the performance of the LoRa network for monitoring floating node. The first parameter was PDR, and the formula can be written as in Equation 3.

$$
P D R=\frac{\sum \operatorname{Pr}}{\sum \operatorname{Ps}} X 100 \%
$$

where:

- PDR is the packet delivery ratio,

- $\quad \sum P r$ is the total packet received,

- $\quad \sum$ Ps is the total packet sent

The second parameter is PER and the formula is written as in the form of Equation 4.

$$
P E R=\frac{\sum \operatorname{Pre}}{\sum \operatorname{Pr}} X 100 \%
$$

where:

- PER is the packet error rate,

- $\quad \sum$ Pre is the total packet received and error,

- $\quad \sum \operatorname{Pr}$ is the total packet received

Table 7 presents PDR, a comparison between the packets sent by the floating solar node and the packets received by the receiver. The comparison determined if packet loss occured while testing the LoRa connection. If the packets received by the LoRa-Raspberry were fewer than 100, it meant that there was packet loss. Packets sent by the node on the lake have been received by the broker, but not without errors. As presented in Table 7, from the tests conducted by sending 100 packets, the first test with a distance of $150 \mathrm{~m}$ managed to obtain $100 \%$ of the packets sent, while with a longer distance of $300 \mathrm{~m}$ in the second test it was apparent that $5 \%$ of the packets were not received.

Table 7

PDR Testing

\begin{tabular}{cccc}
\hline Range & $\sum \operatorname{Pr}$ & $\sum$ Ps & PDR \\
\hline 150 Meters & 100 & 100 & $100 \%$ \\
300 Meters & 95 & 100 & $95 \%$ \\
\hline
\end{tabular}

Table 8

PER Testing

\begin{tabular}{cccc}
\hline Range & $\sum$ Pre & $\sum$ Pr & PER \\
\hline 150 Meters & 2 & 100 & $2 \%$ \\
300 Meters & 7 & 100 & $7 \%$ \\
\hline
\end{tabular}

Table 8 presents PER, wich is used to determine the number of corrupted data obtain by the receiver. Corrupted data were those unsuccessfully received but were experiencing an error in the data payload itself, due to either unreadable or partially damaged data. Two percent of the data experienced an error on the $150 \mathrm{~m}$ test and $7 \%$ in the $300 \mathrm{~m}$. By using the default settings on LoRa, it can be concluded that from the data collected throughout the project, the distance that can be handled by LoRa with the default settings and specification can be up to $300 \mathrm{~m}$ in a safe and open distance. Again, it can be further upgraded as stated in the research by Bor et al. (2016) and Augustin et al. (2016). Based on the testing, LoRa was found to be suitable for monitoring floating node. The coverage area from LoRa was wide range with a stable connection.

\section{Conclusion}

The results obtained are presented as follows. The prototype succeeded in stabilizing the energy input from the solar panel by adjusting the axis accordingly. The results obtained proved that the tracker used successfully answered the initial problem with evidence that the energy and illuminance were bigger and stable than the fixed solar.

With a 95\% PDR up to $300 \mathrm{~m}$ on a default setting, LoRa module was found to be a good tool for monitoring the nodes on rural areas in view of the reliability and practical uses of the module itself, especially in an environment with limited Internet connection. Also, it is definitely better than a wired connection in terms of cost management. LoRa can be the main communication tool that is reliable at a close distance and can potentially be even better with different settings and gears for any commercial uses in the future.

A single-axis solar tracker was found capable of reaching up to $30 \%$ more energy on ordinary solar panels, whereas the floating vertical single-axis solar tracker got about $17 \%$ more than the floating fixed solar panel, as observed in Figure 7, indicating a significant change. In conclusion, the vertical single-axis solar tracker might not be as effective as expected for use on floating solar nodes, 
but it can easily be upgraded with better equipment and parts for further research. Moreover, the research suggests that for commercial uses, the solar tracking node and tracking system have to be more robust.

Further research and testing should focus more on the configuration of the LoRa module for various conditions ranging from extended distance, using different spreading factors, bandwidth and coding rates. The used of better hardware such as antennas with greater $\mathrm{dB}$ than the one used here is affect test results.

The servo from this research not good enough to be actuator, it is suggested to use a different and stronger actuator for the tracker and experiment with different sensors to further increase the voltage generated by the solar panels and to use the materials that are more robust and adequate. To improve functionality, a gyro sensor can be added to the floating solar tracker and other data monitoring sensors such as the energy used in the actuator and the LoRa module. It should also add other testing factors that will affect the results obtained by the node such as wind speed and battery usage.

\section{Acknowledgments}

Thank you to the Internet of Things Studio, Telkom University which has become a place for the researchers to develop this journal research. Hopefully, this research can contribute to the advancement of technology in Indonesia.

\section{References}

Adelantado, F., Vilajosana, X., Tuset-Peiro, P., Martinez, B., Melia-Segui, J., \& Watteyne, T. (2017). Understanding the Limits of LoRaWAN. IEEE Communications Magazine.

Augustin, A., Yi, J., Clausen, T., \& Townsley, W. (2016). A Study of LoRa: Long Range \& Low Power Networks for the Internet of Things. Sensors, 16(9), 1466.

Bor, M. C., Roedig, U., Voigt, T., \& Alonso, J. M. (2016). Do LoRa Low-Power Wide-Area Networks Scale?. Proceedings of the 19th ACM International Conference on Modeling, Analysis and Simulation of Wireless and Mobile Systems - MSWiM '16, New York, USA.

Bushong, S. (2016). Advantages and disadvantages of a solar tracker system. https://www.solarpowerworldonline.com/ 2016/05/advantages-disadvantages-solar-trackersystem/. Accessed on 6 September 2019.

Chin, C. S., Babu, A., \& McBride, W. (2011). Design, modeling, and, testing of a standalone single axis active solar tracker using MATLAB/Simulink. Renewable Energy, 36(11), 3075-3090

Choi, Y.-K. (2014). A Study on Power Generation Analysis of Floating PV System Considering Environmental Impact. International Journal of Software Engineering and Its Applications, 8(1) ,75-84

Georgiou, O., \& Raza, U. (2017). Low Power Wide Area Network Analysis: Can LoRa Scale?. IEEE Wireless Communications Letters.

Hevner, A. R., March, S. T., Park, J., \& Ram, S. (2004). Design science in information systems research. MIS Quarterly: Management Information Systems.

Hoeller, A., Souza, R. D., Lopez, O. L. A., Alves, H., de Noronha Neto, M., \& Brante, G. (2018). Analysis and Performance Optimization of LoRa Networks With Time and Antenna Diversity. IEEE Access, 6, 32820-32829.

Hui, S. F., Ho, H. F., Chan, W. W., Chan, K. W., Lo, W. C., \& Cheng, K. W. E. (2017). Floating solar cell power generation, power flow design and its connection and distribution. 7th International Conference on Power
Electronics Systems and Applications - Smart Mobility, Power Transfer \& Security (PESA).

Lavric, A., \& Popa, V. (2017). Internet of Things and LoRa ${ }^{\mathrm{TM}}$ LowPower Wide-Area Networks: A survey. 2017 International Symposium on Signals, Circuits and Systems (ISSCS).

Lee, J. F., and Rahim, N. A. (2013). Performance comparison of dual-axis solar tracker vs static solar system in Malaysia. IEEE Conference on Clean Energy and Technology (CEAT).

Lee, W. K., Schubert, M. J. W., Ooi, B. Y., \& Ho, S. J. Q. (2018). Multi-Source Energy Harvesting and Storage for Floating Wireless Sensor Network Nodes with Long Range Communication Capability. IEEE Transactions on Industry Applications.

LoRa Alliance. (2018). LoRaWAN 1.0.3 specification. https://loraalliance.org/. Accessed on 6 September 2019.

Luque, A. L., \& Viacheslav, A. (2007). Concentrator Photovoltaics. Berlin, Heidelberg: Springer Berlin Heidelberg, 130.

Luque, H. I., Quéméré, G., Cervantes, R., Laurent, O., Chiappori, E., \& Chong, J. Y. (2012). The Sun Tracker in Concentrator Photovoltaics. Springer Series in Optical Sciences, 61-93.

Mabon, M., Gautier, M., Vrigneau, B., Gentil, M. L., \& Berder, O. (2019). The Smaller the Better: Designing Solar Energy Harvesting Sensor Nodes for Long-Range Monitoring. Hindawi, Wireless Communications and Mobile Computing.

Omar, M. F., Trigunarsyah, B., \& Wong, J. (2009). A design science approach for consultant selection decision support system. 4th International Conference on Cooperation and Promotion of Information Resources in Science and Technology.

Peffers, K., Tuunanen, T., Rothenberger, M. A., \& Chatterjee, S. (2007). A design science research methodology for information systems research. Journal of Management Information Systems.

Rani, P., Singh, O., \& Pandey, S. (2018). An Analysis on Arduino based Single Axis Solar Tracker. 5th IEEE Uttar Pradesh Section International Conference on Electrical, Electronics and Computer Engineering (UPCON).

Sahu, A., Yadav, N., \& K. Sudhakar. (2016). Floating photovoltaic power plant: A review. Renewable and Sustainable Energy Reviews, 66, 815-824.

Shuda, J. E., Rix, A. J., \& Booysen, M. J. (2018). Towards ModuleLevel Performance and Health Monitoring of Solar PV Plants Using LoRa Wireless Sensor Networks. IEEE PES/IAS PowerAfrica.

Shufat, S. A. A., Kurt, E., \& Hancerlioğulları, A. (2016). Modeling and Design of Azimuth-Altitude Dual Axis Solar Tracker for Maximum Solar Energy Generation. International Journal of Renewable Energy Development, 8(1), 7-13.

Suwastika, A. N., Prabowo, S., \& Erfianto, B. (2016). Upwelling Solution Prototype Using Wireless Sensor Network. International Journal on Information and Communication Technology (IJoICT) -s 2356-5462.

Turmudzi, M., Rakhmatsyah, A., Wardana, A. A. (2019). Analysis of Spreading Factor Variations on LoRa in Rural Areas. International Conference on ICT for Smart Society (ICISS).

Tsao, W. C., Zeng, Q. C., Yeh, Y. H., Tsai, C. H., Hong, H. F., Chen, C. Y., Lin, T. Y., Huang, Y. Y., Tsao, C. W., Pan, J. W., \& Wang, C. M. (2019). Efficiency evaluation of a hybrid miniaturized concentrated photovoltaic for harvesting direct/diffused solar light. Journal of Optics, 21(3), 35901.

Vangelista, L. (2017). Frequency Shift Chirp Modulation: The LoRa Modulation. IEEE Signal Processing Letters.

Wang, S., Leblanc, S. G., Fernandes, R., \& Cihlar, J. (2002) Diurnal variation of direct and diffuse radiation and its impact on surface albedo. International Geoscience and Remote Sensing Symposium (IGARSS).

Wardana, A. A., Rakhmatsyah, A., Minarno, A. E., \& Anbiya, D. R. (2019). Internet of Things Platform for Manage 
Multiple Message Queuing Telemetry Transport Broker Server. Kinetik: Game Technology, Information System,
Computer Network, Computing, Electronics, and Control, 4(3), 197.

(C) 2020. This article is an open access article distributed under the terms and conditions of the Creative Commons Attribution (CC BY) license (http://creativecommons.org/licenses/by/4.0/) 